University of Nebraska - Lincoln

DigitalCommons@University of Nebraska - Lincoln

Educational Psychology Papers and

Publications

Educational Psychology, Department of

2008

Contributions of Children's Temperament to Teachers' Judgments of Social Competence from Kindergarten through Second Grade

Kathleen Moritz Rudasill

University of Nebraska-Lincoln, kmrudasill@vcu.edu

Timothy R. Konold

University of Virginia, tk2e@virginia.edu

Follow this and additional works at: https://digitalcommons.unl.edu/edpsychpapers

Part of the Educational Psychology Commons

Rudasill, Kathleen Moritz and Konold, Timothy R., "Contributions of Children's Temperament to Teachers' Judgments of Social Competence from Kindergarten through Second Grade" (2008). Educational Psychology Papers and Publications. 128.

https://digitalcommons.unl.edu/edpsychpapers/128

This Article is brought to you for free and open access by the Educational Psychology, Department of at DigitalCommons@University of Nebraska - Lincoln. It has been accepted for inclusion in Educational Psychology Papers and Publications by an authorized administrator of DigitalCommons@University of Nebraska - Lincoln. 


\title{
Contributions of Children's Temperament to Teachers' Judgments of Social Competence from Kindergarten through Second Grade
}

\author{
Kathleen Moritz Rudasill \\ College of Education and Human Development \\ University of Louisville \\ Timothy R. Konold \\ Curry School of Education \\ University of Virginia \\ Corresponding author - Kathleen Moritz Rudasill
}

\begin{abstract}
Research Findings: Children's social competence has been linked to successful transition to formal school. The purpose of this study was to examine the contributions of children's temperament to teachers' ratings of their social competence from kindergarten through 2nd grade. Children $(N=1,364)$ from the National Institute of Child Health and Human Development Early Child Care Research Network participated in this study. Mothers rated children's shyness, attentional focusing, and inhibitory control with the Children's Behavior Questionnaire at 4 $1 \frac{1}{2}$ years, and teachers rated children's social competence with three subscales (cooperation, assertion, and self-control) of the Social Skills Rating System at kindergarten, 1st, and 2nd grade. Latent growth curve analysis indicated that both shyness and effortful control contributed to children's social competence. Bolder children were likely to have higher assertion ratings, and shyer children with greater attentional focusing were likely to have higher assertion ratings. Shyer children and children with greater inhibitory control and attentional focusing were likely to have higher teacher ratings of self-control and cooperation.

Practice or Policy: Findings highlight the importance of considering child temperament characteristics when understanding children's social competence and successful adjustment to kindergarten. Information may help parents, preschool teachers, and early elementary teachers prepare children who may be at particular risk for lower social competence.
\end{abstract}




\section{$\diamond \diamond \diamond$}

The transition to formal schooling is often challenging for children, particularly for those who enter school with limited exposure to structured interactions with teachers and other children. Although early elementary school presents both academic and social challenges, evidence points to the importance of children's social adjustment for ensuring long-term success in school (Hamre \& Pianta, 2001; Ladd \& Burgess, 1999; Ladd, Herald, \& Kochel, 2006). A characteristic that has been linked to successful transition to school is social competence (Denham, 2006), the ability to effectively navigate social situations for positive developmental outcomes (Dodge, Pettit, McClaskey, \& Brown, 1986; Rubin, Bukowski, \& Parker, 1998). Therefore, the purpose of this study was to understand the antecedents of young children's social competence. Specifically, this study aimed to examine the contributions of children's temperament to teachers' ratings of their social competence from kindergarten through second grade.

According to Ladd et al. (2006), children's social competence promotes school readiness by easing children's adjustment to the myriad of "social school entry tasks" (p. 119) associated with the transition to formal schooling. Such tasks include behavioral-interactional tasks (i.e., initiating and responding to social advances by peers and teachers, and behaving prosocially; p. 121) and relational tasks (i.e., building positive relationships with peers and teachers; p. 125). Thus, in addition to increased academic demands, children must adjust to an unfamiliar environment, new peers, and higher expectations for self-regulation (e.g., following directions), all with decreased adult supervision (Ladd et al., 2006). Indeed, many children arrive in kindergarten unprepared to meet the social demands of the classroom. As an example, in a study of 3,595 kindergarten teachers, $46 \%$ of teachers indicated that at least half of their students showed difficulty following directions in the classroom (Rimm-Kaufman, Pianta,\& Cox, 2000). From this perspective, social competence smoothes children's transitions to school by promoting positive relationships, and positive relationships further social and academic development by serving as support systems for children as they meet the social and academic demands of school (Denham, 2006; Ladd, Birch, \& Buhs, 1999; Thompson \& Happold, 2002).

The present study used a "child effects model" (Rimm-Kaufman \& Pianta, 2000) in understanding children's adjustment to school. Building upon existing research supporting the role of child characteristics (e.g., persistence, approach/ withdrawal, communicative ability, numeracy skills) in children's readiness for school and successful school transitions (Blair, 2002; Schoen \& Nagle, 1994; Skarpness \& Carson, 1986; Zill, Collins, West, \& Hausken, 1995), the present 
study aimed to understand the extent to which children's temperament (specifically, shyness and effortful control) contributes to their social competence from kindergarten through second grade.

\section{Social Competence and School Outcomes}

Social competence has been linked to children's social and academic outcomes in school and has been connected to the quality of their relationships with others in school, such as peers and teachers. For example, social skill growth through prosocial behavior (e.g., turn taking) and negotiation (e.g., compromise) has been linked to positive peer relationships, and the quality of young children's peer relationships has been linked to their successful socioemotional adjustment to kindergarten (Eisenberg et al., 1995; Ladd \& Price, 1987; Rubin, Bukowski, \& Parker, 2006). A similar relationship has been found with teacher-child relationships, such that social competence may facilitate children's positive relationships with teachers, and positive relationships with teachers can provide a behavioral model for children's growth in social competence (Hamre \& Pianta, 2001; Mashburn \& Pianta, 2006). For example, Pianta, Steinberg, and Rollins (1995) found that positive teacher-child relationships in kindergarten served as protective factors for children. That is, for children most at risk for difficulties building social competence and adjusting to school, those in positive teacher-child relationships in kindergarten performed better than expected.

Social competence appears to be related to academic competence as well, such that growth in one competency facilitates growth in the other. The school environment places demands on both academic and social skills. For example, preschool children with greater cognitive and language abilities developed better social skills and more effective coping mechanisms for stress than their peers with lower levels of ability (Coplan \& Armer, 2005; Rubin \& Coplan, 2004). Skills such as following directions and productively participating in group activities are major contributors to instructional activities; a child who does not follow directions or participate productively in activities will, most obviously, miss out on classroom instruction and, more subtly, learn to dislike school and possibly distrust himself or herself to participate in class (Elliott, Malecki, \& Demaray, 2001). In this way, social competence skills can be viewed as "academic enablers" (Elliott et al., 2001, p. 22), promoting achievement via skills such as listening, questioning, and attending to class activities.

\section{Contributors to Social Competence}

The extant literature suggests that some temperamental characteristics contribute to children's social competence (Rubin et al., 2006). Children who display high 
levels of emotionality are likely to show antisocial behavior, such as aggression, fighting, or possessiveness (Rubin, Burgess, Dwyer, \& Hastings, 2003). Similarly, children in preschool through upper elementary school who are shy or withdrawn are likely to be less prosocial than their bolder peers (Coplan, Rubin, Fox, Calkins, \& Stewart, 1994; Eisenberg, Shepard, Fabes, Murphy, \& Guthrie, 1998; Rydell, Bohlin, \& Thorell, 2005). For example, Wichmann, Coplan, and Daniels (2004) found that socially withdrawn children (identified by peers) in upper elementary school showed lower levels of social competence than their nonwithdrawn peers. Specifically, socially withdrawn children were more likely to have negative perceptions of their social skills and to interact with others in socially withdrawn and nonassertive ways. In another study, Rydell and colleagues found that shyer preschool children (those who withdrew from the unfamiliar) were less likely than their bolder counterparts to initiate social interactions with peers. On the other hand, there is evidence that shy children are more likely to display empathy and conscience, skills indicative of social competence (Rothbart, Ahadi, \& Evans, 2000; Rydell et al., 2005). Thus, the direction of relationships between children's temperament and social competence is not clear, and, in fact, temperamental dimensions may contribute differentially to different aspects of social competence.

A child's ability to regulate emotional and behavioral reactions to the environment has been linked to social competence. Children's display of high levels of effortful control has been related to greater social competence and the ability to form positive relationships with others in preschool and kindergarten (Goldsmith, Aksan, Essex, Smider, \& Vandell, 2001). Four- and five-year-old children with greater regulatory abilities, specifically attentional control, were less likely to display antisocial behavior, such as stealing or hitting (Kochanska, 1997). It is interesting that, through their exploration of the interaction between 4- and 5-yearold children's approach/withdrawal tendencies (based on social interactions) and their regulatory abilities, Rubin, Coplan, Fox, and Calkins (1995) discovered that these elements of children's temperament worked together to influence social competence in preschool children. For approach-oriented children, low levels of regulation contributed to antisocial behaviors (i.e., aggressive toward peers, disruptive in class), and high levels of regulation contributed to prosocial behaviors toward peers. For withdraw-oriented children, low levels of regulation contributed to reticent and anxious behavior with peers, and high regulation contributed to independent play.

Collectively, these findings suggest a relationship between young children's temperament characteristics and their social competence. However, there is little research on the predictive value of young children's shyness and effortful control to their later social competence (i.e., kindergarten through second grade). In addition, a recent review of temperament and social development literature pointed to a paucity of research aimed at understanding how temperament characteristics interact to influence young children's social competence (Sanson, Hemphill, \& Smart, 2004). 
Research also suggests a gender difference in children's social competence. Among 4- and 5-year-olds, boys are more likely than girls to show antisocial and aggressive behavior (Kochanska, 1997), and girls may also be more inclined to behave in relationally, rather than physically, aggressive ways (Dodge, Coie, \& Lynam, 2006). Moreover, there is evidence that girls are more likely than boys to show prosocial behavior (Kochanska, 1997). Therefore, the purpose of this study was to understand how children's temperament characteristics contribute to their social competence considering gender.

\section{Temperament}

Broadly defined, temperament is an individual's biologically based, multidimensional (e.g., emotionality, activity level, shyness, effortful control) style of responding to the environment (Thomas \& Chess, 1977). Although it is relatively stable, researchers agree that the nature of temperament emerges through interactions between the individual's genetic makeup and the environment (Kagan \& Fox, 2006; Rothbart \& Bates, 1998, 2006). The dimensions of temperament comprise two systems: the biologically based reaction to the environment (i.e., reactivity), and the ability to regulate reactivity (i.e., regulation). The literature suggests that the reactive and regulatory dimensions of temperament that are most salient to understanding children's social competence are shyness (an element of reactivity) and effortful control (the ability to regulate; Coplan et al., 1994; Eisenberg et al., 1998; Kochanska, 1997; Rothbart et al., 2000; Rubin et al., 1995; Wichmann et al., 2004).

Shyness, also referred to as behavioral inhibition (Kagan, 1998), approach/ withdrawal (Thomas \& Chess, 1977), and reticence (Rubin, 1982), refers to an individual's tendency to approach or withdraw from new people or situations. An individual with a high level of shyness is withdraw oriented. An individual with a low level of shyness is approach oriented (Asendorpf \& Meier, 1993; Kagan, 1994). For example, in the company of unfamiliar children, a very shy child may spend time observing the children playing before deciding whether to join them. However, a child who is not shy (i.e., who is bold) is likely to immediately join the children's activities.

Effortful control refers to an individual's ability to suppress an inappropriate response and activate an appropriate one (Kochanska, Murray, \& Harlan, 2000; Rothbart \& Bates, 1998, 2006). Thus, effortful control is the temperamental system that regulates an individual's reactive systems, such as shyness (Henderson \& Fox, 1998). There are two elements of effortful control: the first is the ability to inhibit an inappropriate response (inhibitory control), and the second is the ability to shift attention and focus on alternative stimuli, thus activating a different response (attentional focusing; Rothbart \& Bates, 2006). To illustrate, a child with high effortful control who is teased by peers on the playground may be likely 
to respond by ignoring the jeers, talking to an adult, or calmly telling the peers to stop their teasing. A child with low effortful control may be likely to respond with aggression, yelling, or frustrated crying.

Taken together, the research on shyness and effortful control suggests that these dimensions of temperament may contribute to children's social success in school. The extant literature shows that characteristics such as social withdrawal and aggression contribute to children's social competence. However, few studies have examined how children's characteristics interact to contribute to social outcomes, and none has examined the extent to which young children's shyness and effortful work together to contribute to their teachers' perceptions of the children's social competence from kindergarten through second grade, considering gender.

The primary purpose of this work was to examine the relationships between mother's ratings of children's temperament (i.e., shyness, attentional focusing, and inhibitory control) at 4 $\frac{1}{2}$ years of age and children's teacher-rated social competence (i.e., assertion, self-control, and cooperation) in kindergarten through second grade. In addition, interactions among temperament variables were evaluated in order to tease out potential moderating effects, and multigroup analyses were conducted for gender groups to assess differential effects for boys and girls. Structures of the social competence variables were modeled within the framework of latent growth curve analysis (LGCA), and the child temperament predictors were modeled to estimate their influence on children's initial status and growth across the three time points.

\section{Method}

\section{Participants}

Children and their kindergarten teachers from the National Institute of Child Health and Human Development (NICHD) Early Child Care Research Network (ECCRN) participated in this study. Women delivering in hospitals from across the United States (Little Rock, AR; Irvine, CA; Lawrence, KS; Boston, MA; Philadelphia, PA; Pittsburgh, PA; Charlottesville, VA; Morganton, NC; Seattle, WA; and Madison, WI) were asked to participate in 1991. There were 8,986 new mothers in these hospitals; 5,416 were found to be eligible for study participation and agreed to talk to researchers. From that group, 1,364 mother-infant dyads were randomly selected as study participants. The NICHD Study of Early Child Care includes three phases of data collection. Data for this study were collected when children were between $4 \frac{1}{2} 2$ years of age and second grade $(N=1,364)$. Study children included 705 boys and 659 girls. The sample was primarily White $(n=$ 1,097); the mean number of years of education for participants' mothers was 14.2 $(S D=2.5)$. 


\section{Procedures}

Data from children at $4 \frac{1}{2}$ years were gathered from mothers during a laboratory session. The kindergarten, first grade, and second grade data were collected from teachers each school year. Data were collected at approximately one-year intervals; children's mean ages in months at each data collection point were as follows: $4 \frac{1}{2} 2$ years $(M=55.5, S D=1.2)$, kindergarten $(M=67.2, S D=3.6)$, first grade $(M=82.9, S D=3.8)$, and second grade $(M=95.4, S D=4.0)$. Children in this study attended 827 classrooms in 747 schools within 295 school divisions in 32 states. The Manuals of Operation of the NICHD ECCRN (1993) contain additional information about the sample, selection processes, data collection, instrument, and procedures.

\section{Measures}

Children's Behavior Questionnaire. Scores from the shyness, inhibitory control, and attentional focusing subscales of the Children's Behavior Questionnaire (Rothbart, Ahadi, \& Hershey, 1994) were used to assess children's shyness and effortful control at age $4 \frac{1}{2} 2$ years. The Children's Behavior Questionnaire is a parent-report instrument for children from ages 3 to 8 . On it, parents rated their children's behaviors during the past 6 months on a scale from 1 (extremely untrue) to 7 (extremely true).

Shyness was measured by using scores from the shyness subscale, such that a higher score indicated greater shyness (i.e., a shyer child). Examples of items from this subscale are "Sometimes seems nervous when talking to adults s/he has just met" and "Acts shy around new people." The internal consistency for this subscale with the current sample was high (.87).

Effortful control was measured with scores on the inhibitory control and attentional focusing subscales, such that higher scores indicated greater effortful control. The inhibitory control subscale measures a child's ability to respond readily to parent or teacher directions; examples of items from this subscale are "Can easily stop an activity when s/he is told 'no'" and "Has difficulty waiting in line for something" (reversed). Internal consistency with the current sample was .74. The attentional focusing subscale measures a child's ability to concentrate and focus on an activity; examples of items from this subscale are "Has a hard time concentrating on an activity when there are distracting noises" (reversed) and "When building or putting something together, becomes very involved in what s/ he is doing, and works for long periods." Cronbach's alpha with the current sample was .74 .

Social Skills Rating System. Children's social competence was assessed through kindergarten, first-, and second-grade teacher report on the Social Skills Scale of the Social Skills Rating System-Teacher Form (Gresham \& Elliott, 1990). 
For each item, teachers rated the study child's behavioral frequency on a 3-point scale, where $0=$ never, $1=$ sometimes, and $2=$ very often. There were three subscales: cooperation, assertion, and self-control. The cooperation subscale measures a child's behavior in response to teacher behavioral queues and classroom demands. Items include "Finishes class assignments within time limits," "Attends to your [the teacher's] instructions," and "Easily makes transition from one classroom activity to another." The assertion subscale is a measure of a child's tendency to initiate interactions with peers. Items from this subscale include "Introduces herself or himself to new people without being told," "Invites others to join in activities," and "Initiates conversations with peers." The self-control subscale measures a child's behavior in response to stressors. Items from this subscale include "Controls temper in conflict situations with adults," "Cooperates with peers without prompting," and "Responds appropriately when pushed or hit by other children." The NICHD ECCRN (1993) manuals report high internal reliability for scores on these subscales when rated by kindergarten teachers (cooperation: .92, assertion: .86, self-control: .87).

\section{Data Analyses}

Prominent features of the primary model that was considered for the teacher-rated social competence variable of assertion are illustrated in Figure 1. Similar models were examined for teacher ratings of self-control and cooperation. Model parameterizations were omitted from this illustration for ease of presentation but are described in text below. The upper corner of Figure 1 illustrates the manner in which the outcome variables (e.g., assertion) were modeled through LGCA. LGCA allows for the estimation of both latent intercept and latent slope terms, as illustrated by the ellipses. The specification of a latent intercept allows for the estimation of initial status (i.e., fall of kindergarten), and the latent slope provides a measure of growth across time. The measured variables, teachers' ratings of these behaviors, are distinguished from the directly unobserved latent variables by their enclosure in boxes. Growth curves for each of the three teacher-rated social competence variables were evaluated separately to estimate the initial status (i.e., intercept) of children on these variables as well as their growth (i.e., slope) across the three time points. Because the intervals between the three waves of teacher-reported measures of student behavior were approximately equally spaced, parameterizations for the slope factors were set at 0,1 , and 2 to model the approximate lag time between measurement occasions.

Mothers' temperament ratings of children at $4 \frac{1}{2} 2$ years were specified to have a direct effect on children's initial status and growth in social competence, as illustrated by the single-headed arrows leading from the temperament set (i.e., attentional focusing, inhibitory control, and shyness) and their interactions to the intercept and slope factors. Again, separate models were examined for each of the 


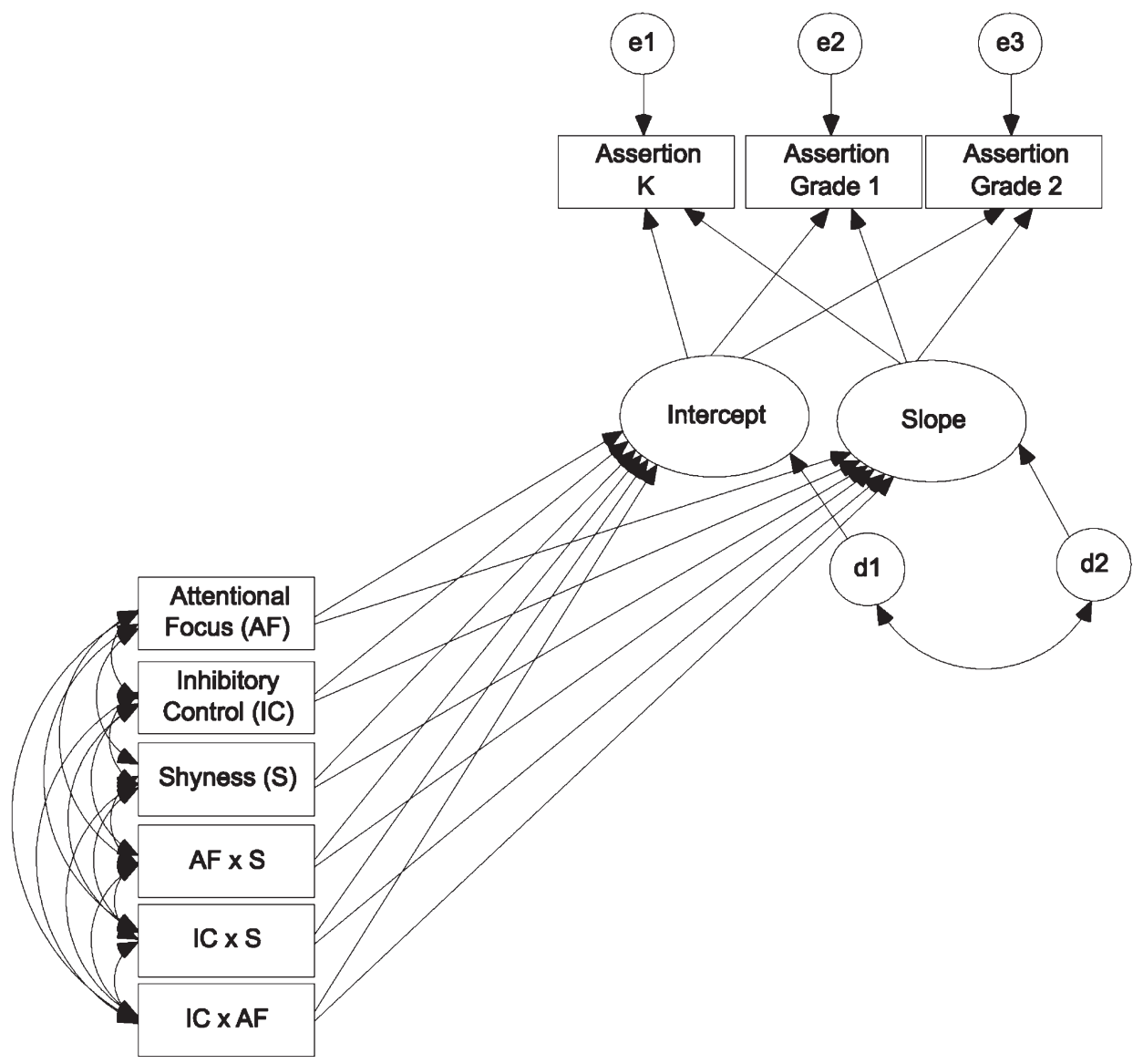

Figure 1. Full unconstrained model with predictors of initial status and growth of assertion. $\mathrm{K}=$ kindergarten.

three social competence variables of assertion, self-control, and cooperation. The curved double-headed arrows in Figure 1 illustrate the freely estimated correlations between the intercept and slope disturbance terms, and measures of temperament and their interactions.

Following estimation of the full unconstrained model as shown in Figure 1, paths for nonsignificant interactions among the temperament variable set were fixed to 0 in search of more parsimonious solutions. Nested model comparisons between the unconstrained and restricted models were evaluated with chi-square difference $\left(\chi_{D}^{2}\right)$ tests. Following a nonsignificant decline in fit, multigroup analyses were conducted on the reduced models to examine the invariance of the substantive influences of temperament on the initial status and growth of the social competence variables. Two multigroup models were evaluated to test for invari- 
ance between boys and girls. The first was a general form model in which no cross-group constraints were imposed on the parameter estimates between boys and girls. This general form model served as a baseline model for evaluating further cross-group constraints imposed on parameter estimates and evaluated only whether the general model specification of fixed (including nonsignificant interactions fixed to 0 ) and free paths was tenable for the two groups. The second multigroup model imposed cross-group equality constraints on the paths linking the temperament variables to latent initial status and growth factors underlying the social competence variables. Nested model comparisons between the two multigroup models were evaluated with chi-square difference $\left(\chi_{D}^{2}\right)$ tests.

All models were estimated with the Analysis of Moment Structures 7.0 program using full information maximum likelihood estimation to accommodate some missing data points on covariance matrices. Numerous measures of model fit exist for evaluating the quality of measurement models, most developed under a somewhat different theoretical framework focusing on different components of fit (Browne \& Cudeck, 1993; Hu \& Bentler, 1995). For this reason, it is generally recommended that multiple measures be considered to highlight different aspects of fit (Tanaka, 1993). Use of the chi-square statistic was limited to testing differences $\left(X_{D}^{2}\right)$ between competing models. As a stand-alone measure of fit, chi-square is known to reject trivially misspecified models estimated on large sample sizes (Hu \& Bentler, 1995; Kaplan, 1990; Kline, 2005). The chisquare ratio $\left(\chi^{2} / d f\right)$ was, however, used to evaluate stand-alone models. This index tends to be less sensitive to sample size, and values less than 3 (or in some instances 5) are often taken to indicate acceptable models (Kline, 2005). Four additional measures of fit were considered in evaluating model quality. These included the Bentler-Bonett normed fit index (NFI), Tucker-Lewis Index (TLI), comparative fit index (CFI), and root mean square error of approximation (RMSEA). These four measures generally range between 0 and 1.0. Traditionally, values of .90 or greater are taken as evidence of good-fitting models (Bentler \& Bonett, 1980). However, more recent research suggests that better fitting models produce values around .95 (Hu \& Bentler, 1999). Alternatively, smaller RMSEA values support better fitting models, with values of .10 or less indicating good fit (Fan, Thompson, \& Wang, 1999).

\section{Results}

Means, standard deviations, ranges, and correlations among the measured variables are presented in Table 1 . Mean values for temperament scores indicated that children in the current sample typically displayed more attentional focusing $(M=4.71)$ and inhibitory control $(M=4.66)$ than shyness $(M=3.52)$. In terms of social competence, kindergarten, first-, and second-grade scores, respectively, for children in this sample indicated lower assertion (Ms $=12.93,13.25$, 
Table 1. Correlations and Descriptive Statistics for Measured Variables

\begin{tabular}{|c|c|c|c|c|c|c|c|c|c|c|c|c|}
\hline \multirow[b]{2}{*}{ Variable } & \multicolumn{3}{|c|}{ Predictor } & \multicolumn{3}{|c|}{ Assertion } & \multicolumn{3}{|c|}{ Self-Control } & \multicolumn{3}{|c|}{ Cooperation } \\
\hline & $\overline{\mathrm{AF}}$ & IC & $\bar{S}$ & $\mathrm{~K}$ & G1 & G2 & K & G1 & G2 & K & G1 & G2 \\
\hline \multicolumn{13}{|c|}{ Predictors } \\
\hline $\mathrm{AF}$ & - & .53 & .01 & .11 & .13 & .17 & .13 & .19 & .18 & .23 & .29 & .28 \\
\hline IC & & - & .06 & .10 & .10 & .18 & .20 & .20 & .24 & .29 & .25 & .26 \\
\hline$S$ & & & - & -.17 & -.13 & -.09 & .10 & .10 & .09 & .17 & .13 & .13 \\
\hline \multicolumn{13}{|l|}{ Assertion } \\
\hline K & & & & - & .34 & .32 & .50 & .13 & .11 & .45 & .19 & .19 \\
\hline G1 & & & & & - & .40 & .22 & .51 & .19 & .26 & .48 & .26 \\
\hline G2 & & & & & & - & .20 & .26 & .59 & .27 & .35 & .51 \\
\hline \multicolumn{13}{|c|}{ Self-control } \\
\hline K & & & & & & & - & .39 & .37 & .65 & .29 & .32 \\
\hline G1 & & & & & & & & - & .44 & .34 & .61 & .38 \\
\hline G2 & & & & & & & & & - & .34 & .38 & .61 \\
\hline \multicolumn{13}{|c|}{ Cooperation } \\
\hline K & & & & & & & & & & - & .47 & .49 \\
\hline G1 & & & & & & & & & & & - & .60 \\
\hline G2 & & & & & & & & & & & & - \\
\hline$M$ & 4.71 & 4.66 & 3.52 & 12.93 & 13.25 & 13.67 & 15.18 & 15.17 & 15.44 & 15.93 & 15.49 & 15.80 \\
\hline$S D$ & 0.85 & 0.78 & 1.10 & 4.17 & 3.88 & 4.03 & 3.71 & 3.71 & 3.96 & 4.04 & 4.08 & 4.02 \\
\hline Range & $1-7$ & $1-7$ & $1-7$ & $0-20$ & $0-20$ & $0-20$ & $0-20$ & $0-20$ & $0-20$ & $0-20$ & $0-20$ & $0-20$ \\
\hline
\end{tabular}

$\mathrm{AF}=$ attentional focusing; $\mathrm{IC}=$ inhibitory control; $\mathrm{S}=$ shyness; $\mathrm{K}=$ kindergarten; $\mathrm{G} 1$ =

Grade 1; G2 = Grade 2.

All $r \mathrm{~s} \geq .10$ are significant at $p<.01$. All $r \mathrm{~s} \geq .06$ are significant at $p<.05$.

13.67) than self-control $(M s=15.18,15.17,15.44)$ and cooperation $(M s=15.93$, $15.49,15.80)$. Correlational analyses showed that temperament and social competence subscale scores had low intercorrelations (i.e., less than .3). However, the temperament subscale scores for attentional focusing and inhibitory control were moderately related $(r=.53)$. Outcome variables (cooperation, assertion, and selfcontrol) showed moderate intercorrelations within kindergarten, first, and second grade (e.g., the correlation between assertion and self-control in kindergarten was .50). In addition, children's scores on each outcome variable were moderately correlated across grades (e.g., the correlation between assertion scores in kindergarten and first grade was .34). These relationships were further investigated in the growth models that follow.

Measures of fit for each of the three social competence models (i.e., assertiveness, self-control, and cooperation) and their different specifications as described above are presented in Table 2 . In all instances, the reduced models with nonsignificant interactions fixed to 0 provided good fit and were found to be invariant across gender groups. Accordingly, substantive interpretations were based on the 
Table 2. Overall Model Fit Statistics

\begin{tabular}{|c|c|c|c|c|c|c|c|c|}
\hline \multirow{3}{*}{$\frac{\text { Model }}{\text { Assertiveness }}$} & \multicolumn{8}{|c|}{ Fit Index } \\
\hline & \multirow[t]{2}{*}{$x^{2}$} & \multirow[t]{2}{*}{$d f$} & \multirow[t]{2}{*}{$X_{D}^{2}$} & \multirow[t]{2}{*}{$d f_{D}$} & \multirow[t]{2}{*}{ NFI } & \multirow[t]{2}{*}{ TLI } & \multicolumn{2}{|c|}{ CFI RMSEA } \\
\hline & & & & & & & & \\
\hline Unconstrained & 8.84 & 7 & & & .99 & .99 & 1.0 & .02 \\
\hline Reduced & 9.04 & 11 & 0.20 & 4 & .99 & 1.0 & 1.0 & $<.01$ \\
\hline $\begin{array}{l}\text { General form } \\
\text { multigroup reduce }\end{array}$ & $d^{16.81}$ & 22 & & & .99 & 1.0 & 1.0 & $<.01$ \\
\hline $\begin{array}{l}\text { Constrained } \\
\text { multigroup reduce }\end{array}$ & 20.25 & 30 & 3.44 & 8 & .99 & 1.0 & 1.0 & $<.01$ \\
\hline \multicolumn{9}{|l|}{ Self-control } \\
\hline Unconstrained & 5.47 & 7 & & & 1.0 & 1.0 & 1.0 & $<.01$ \\
\hline Reduced & 10.28 & 13 & 4.81 & 6 & .99 & 1.0 & 1.0 & $<.01$ \\
\hline $\begin{array}{l}\text { General form } \\
\text { multigroup reduce }\end{array}$ & 21.90 & 26 & & & .99 & 1.0 & 1.0 & $<.01$ \\
\hline $\begin{array}{l}\text { Constrained } \\
\text { multigroup reduce }\end{array}$ & $d^{28.03}$ & 32 & 6.13 & 6 & .99 & 1.0 & 1.0 & $<.01$ \\
\hline \multicolumn{9}{|l|}{ Cooperation } \\
\hline Unconstrained & 17.40 & 7 & & & .99 & .99 & .99 & .03 \\
\hline Reduced & 21.90 & 13 & 4.50 & 6 & .99 & .99 & .99 & .02 \\
\hline $\begin{array}{l}\text { General form } \\
\text { multigroup reduce }\end{array}$ & $d^{39.33}$ & 26 & & & .99 & .99 & .99 & .02 \\
\hline $\begin{array}{l}\text { Constrained } \\
\text { multigroup reduce }\end{array}$ & $d^{46.07}$ & 32 & 6.74 & 6 & .99 & .99 & .99 & .02 \\
\hline
\end{tabular}

resulting parameter estimates from these models (see Table 3). Details for each of the three social competence models are provided below.

\section{Assertiveness}

All measures of fit for the unconstrained model were favorable. The NFI, TLI, and CFI were all above .95 for the total sample. In addition, the RMSEA was less than .05 , and $x^{2} / d f=1.26<3.0$ (see Table 2). Inspection of the path coefficients linking the three interaction terms to children's initial status and assertiveness growth indicated a statistically significant relationship between the interaction of attentional focusing and shyness on both the intercept and slope factors. Consequently, the four paths linking the two nonsignificant interactions to the two latent factors were restricted to 0 . This reduced model produced favorable fit statistics and was not found to result in a statistically significant decline in fit when compared to the unconstrained model, $\chi_{D}^{2}(4)=0.20, p>.05$ (see Table 2). 
Table 3. Total Sample Growth Curve Parameter Estimates and Standardized Effects of Predictors on Intercepts and Slopes for Reduced Models

\begin{tabular}{|c|c|c|c|c|c|c|}
\hline \multirow[b]{2}{*}{ Variable } & \multicolumn{2}{|c|}{ Assertiveness } & \multicolumn{2}{|c|}{ Self-Control } & \multicolumn{2}{|c|}{ Cooperation } \\
\hline & $\begin{array}{l}\text { Intercept } \\
\text { Factor }\end{array}$ & $\begin{array}{l}\text { Slope } \\
\text { Factor }\end{array}$ & $\begin{array}{l}\text { Intercept } \\
\text { Factor }\end{array}$ & $\begin{array}{l}\text { Slope } \\
\text { Factor }\end{array}$ & $\begin{array}{l}\text { Intercept } \\
\text { Factor }\end{array}$ & $\begin{array}{l}\text { Slope } \\
\text { Factor }\end{array}$ \\
\hline Intercept estimate & $18.08^{*}$ & $-4.86^{*}$ & $9.26^{*}$ & -0.77 & $5.83^{*}$ & 0.16 \\
\hline$r_{\text {intercept,slope }}$ & \multicolumn{2}{|c|}{-.10} & \multicolumn{2}{|c|}{.03} & \multicolumn{2}{|c|}{.16} \\
\hline Predictor & \multicolumn{6}{|c|}{ Standardized estimates } \\
\hline Attentional focusing (AF) & $-0.30^{*}$ & $0.84^{*}$ & $0.13^{*}$ & 0.11 & $0.22^{*}$ & 0.19 \\
\hline Inhibitory control (C) & 0.08 & 0.17 & $0.24^{*}$ & 0.10 & $0.29^{*}$ & -0.17 \\
\hline Shyness (S) & $-1.10^{*}$ & $1.67^{*}$ & $0.14^{*}$ & 0.01 & $0.21^{*}$ & -0.08 \\
\hline $\mathrm{AF} \times \mathrm{S}$ & $0.94^{*}$ & $-1.70^{*}$ & 0 & 0 & 0 & 0 \\
\hline $\mathrm{IC} \times \mathrm{S}$ & 0 & 0 & 0 & 0 & 0 & 0 \\
\hline $\mathrm{IC} \times \mathrm{AF}$ & 0 & 0 & 0 & 0 & 0 & 0 \\
\hline
\end{tabular}

The resulting reduced model was next subject to multigroup analyses to test for invariance across groups of boys and girls. The general form model suggested that the pattern of free and fixed paths in the reduced model was viable for both groups of children. The NFI, TLI, and CFI were all above .95; the RMSEA was less than .05; and $\chi^{2} / d f=0.76<3.0$ (see Table 2). A second multigroup model imposed cross-group equality constraints on the free paths linking the temperament variables (and the remaining interaction) to the assertiveness intercept and slope factors. Here again, results supported invariance across groups in this constrained model, suggesting that these relationships were equally viable for boys and girls. The NFI, TLI, and CFI were all above .95; the RMSEA was less than .05; $\chi^{2} / d f=$ $0.68<3.0$; and a comparison between the two multigroup models indicated that the additional cross-group constraints imposed on the multigroup model did not result in a statistically significant decline in fit, $\chi^{2}{ }_{D}(8)=3.44, p>.05$ (see Table 2).

Latent growth curve. Summary parameter estimates for the embedded growth curve analysis of assertiveness are provided in Table 3 for the total sample. Although the intercept was statistically significant, there is generally little substantive interest in this estimate within a growth curve analysis. At the same time, the variance of this intercept (5.04) was also statistically significant, indicating that children differed in terms of their levels of assertiveness in kindergarten, $t=5.20, p<.001$. Results also indicated a statistically significant rate of change. The obtained parameter estimate of -4.86 indicated that children's teacher-rated assertiveness declined across the three measurement occasions. When applied to 
the parameterization of the growth rate factor (i.e., $0,1,2)$, children's overall decline from kindergarten to first grade was $1 \times-4.86=-4.86$; from first grade to second grade was $1 \times-4.86=-4.86$; and across all three time points was $2 \times-4.86$ $=-9.72$. The slope variance $(.56)$ was not statistically significant, however, indicating little individual variation among children in teacher reports of assertiveness across the three time points.

The correlation between the intercept and slope factors was negative and small in size (-.10). Although small, the negative value indicated that children with high initial ratings on assertiveness had lower growth rates across the remaining period. That is, children who were initially rated higher on this variable tended to show a slower rate of decline across time than those children who were initially rated lower.

Influences of temperament indicators. Standardized estimates of the direct effects of attentional focusing, inhibitory control, shyness, and the Attentional Focusing $\times$ Shyness interaction on the intercept and slope factors are shown in Table 3. Among these, inhibitory control was the only variable that failed to demonstrate a statistically significant effect on children's initial status or growth on teachers' ratings of assertiveness. The remaining variables were statistically significant with moderate to large influences on children's teacher-rated kindergarten levels of assertiveness and their changes across the time points. Previously described multigroup results indicated that these patterns of relationships were similar for both boys and girls.

The nature of the Attentional Focusing $\times$ Shyness interaction was examined through multigroup analyses conducted between high and low designations of shyness that were identified through a median split. Attentional focusing was specified to have a direct effect on the latent intercept and slope factors, and shyness groups were evaluated for their moderating effects on these relationships. The resulting general form model (as previously described) demonstrated good fit. The NFI, TLI, and CFI were all above .95; the RMSEA was less than .05; and $X^{2} / d f=0.44<3.0$. Cross-group constraints on the path between attentional focusing and the latent intercept resulted in a statistically significant decline in fit, $\chi_{D}^{2}(1)=6.81, p<.05$; whereas equality constraints on the path between attentional focusing and the latent slope did not, $\chi_{D}^{2}(1)=3.68, p>.05$. Thus, the moderating influence of shyness on the relationship between attentional focusing and assertion appeared to be limited to children's initial status on this variable. The relationship between attentional focusing and the assertion intercept was statistically significant, $t=4.17, p<.001$, and moderate (standardized weight $=.30$ ) for children with higher levels of shyness. For children with lower levels of shyness, the relationship was both nonsignificant, $t=0.94, p>.05$, and small (standardized weight $=.07)$.

To summarize, children's assertion in kindergarten was related to their shyness and attentional focusing levels, such that, for shyer children, greater atten- 
tional focusing contributed to greater assertion. In addition, children's assertion ratings declined from kindergarten to second grade; children with higher levels of attentional focusing and shyness were likely to experience greater decreases in assertion from kindergarten through second grade.

\section{Self-Control}

All measures of fit for the unconstrained model were favorable. The NFI, TLI, and CFI were all above .95 for the total sample. In addition, the RMSEA was less than .05 , and $x^{2} / d f=0.78<3.0$ (see Table 2). Inspection of the path coefficients linking the three interaction terms to children's initial status and self-control growth failed to indicate any statistically significant linkages. Consequently, the six paths linking the three nonsignificant interactions to the two latent factors were restricted to 0 . This reduced model produced favorable fit statistics and was not found to result in a statistically significant decline in fit when compared to the unconstrained model, $X_{D}^{2}(6)=4.81, p>.05$ (see Table 2).

The resulting reduced model was next subject to multigroup analyses to test for invariance across groups of boys and girls. The general form model suggested that the pattern of free and fixed paths in the reduced model was viable for both groups of children. The NFI, TLI, and CFI were all above .95; the RMSEA was less than .05; and $\chi^{2} / d f=0.84<3.0$ (see Table 2). A second multigroup model imposed cross-group equality constraints on the free paths linking the temperament variables to the self-control intercept and slope factors. Here again, results supported invariance across groups in this constrained model, suggesting that the model implied that relationships were equally viable for boys and girls. The NFI, TLI, and CFI were all above .95; the RMSEA was less than $.05 ; x^{2} / d f=0.88<3.0$; and a comparison between the two multigroup models indicated that the additional cross-group constraints imposed on the multigroup model did not result in a statistically significant decline in fit, $\chi^{2}{ }_{D}(6)=$ $6.13, p>.05$ (see Table 2).

Latent growth curve. Summary parameter estimates for the embedded growth curve analysis of self-control are provided in Table 3 for the total sample. The intercept (9.26) was found to be statistically significant, as was the variance of this intercept (4.52), $t=5.60, p<.001$. However, neither teachers' ratings of children's self-control across the three time points (slope $=-.77$ ) nor individual variation among children (.49), $t=1.11, p>.05$, were found to be statistically significant. Thus, although no change in students' teacher-reported self-control scores was observed, children did enter kindergarten with individual differences with respect to self-control. The correlation between the intercept and slope factors was near $0(.03)$, indicating little relationship between children's initial status and changes across the three time points. 
Influences of temperament indicators. Standardized estimates of the direct effects of attentional focusing, inhibitory control, and shyness on the intercept and slope factors are shown in Table 3. Each of these three variables was found to have a statistically significant, albeit small, influence on children's initial self-control status in kindergarten. No significant relationships were observed with respect to children's growth. Previously described multigroup results indicated that these patterns of relationships were similar for both boys and girls. To summarize, children with greater attentional focusing, inhibitory control, and shyness were likely to have higher self-control ratings in kindergarten. However, children's scores on these temperament variables did not appear to contribute to growth in self-control between kindergarten and second grade.

\section{Cooperation}

Results from the cooperation model were largely similar to those obtained with the self-control model. Measures of fit for the unconstrained model were favorable. The NFI, TLI, and CFI were all above .95 for the total sample. In addition, the RMSEA was less than .05 , and $x^{2} / d f=2.49<3.0$ (see Table 2). Inspection of the path coefficients linking the three interaction terms to children's initial status and cooperation growth failed to indicate any statistically significant linkages. Consequently, the six paths linking the three nonsignificant interactions to the two latent factors were restricted to 0 . This reduced model produced favorable fit statistics and was not found to result in a statistically significant decline in fit when compared to the unconstrained model, $X_{D}^{2}(6)=$ $4.50, p>.05$ (see Table 2).

The resulting reduced model was next subject to multigroup analyses to test for invariance across groups of boys and girls. The general form model suggested that the pattern of free and fixed paths in the reduced model was viable for both groups of children. The NFI, TLI, and CFI were all above .95; the RMSEA was less than .05; and $\chi^{2} / d f=1.51<3.0$ (see Table 2). A second multigroup model imposed cross-group equality constraints on the free paths linking the temperament variables to the cooperation intercept and slope factors. Here again, results supported invariance across groups in this constrained model, suggesting that the model implied that relationships were equally viable for boys and girls. The NFI, TLI, and CFI were all above .95; the RMSEA was less than .05; $\chi^{2} / d f=1.44<3.0$; and a comparison between the two multigroup models indicated that the additional cross-group constraints imposed on the multigroup model did not result in a statistically significant decline in fit, $\chi_{D}^{2}(6)=6.74, p>.05$ (see Table 2).

Latent growth curve. Summary parameter estimates for the embedded growth curve analysis of cooperation are provided in Table 3 for the total sample. The intercept (5.83) was found to be statistically significant, as was the variance of this intercept (5.68), $t=6.80, p<.001$. However, neither teachers' ratings of chil- 
dren's cooperation across the three time points (slope $=.16$ ) nor individual variation among children (.66), $t=1.54, p>.05$, were found to be statistically significant. Thus, although no change in students' teacher-reported cooperation scores was observed, children did enter kindergarten with individual differences with respect to cooperation. The correlation between the intercept and slope factors was relatively small (.16), indicating that children with high initial ratings on cooperation had somewhat higher growth rates across the remaining period.

Influences of temperament indicators. Standardized estimates of the direct effects of attentional focusing, inhibitory control, and shyness on the intercept and slope factors are shown in Table 3. Each of these three variables was found to have a statistically significant, albeit small, influence on children's initial cooperation status in kindergarten. No significant relationships were observed with respect to children's growth. Previously described multigroup results indicated that these patterns of relationships were similar for both boys and girls. To summarize, children with greater attentional focusing, inhibitory control, and shyness were likely to have higher cooperation ratings in kindergarten. However, children's scores on these temperament variables did not appear to contribute to growth in cooperation between kindergarten and second grade.

\section{Discussion}

This exploration of the antecedents of children's social competence from kindergarten through second grade points to the importance of considering children's temperament. To that end, four main findings emerged from this study. First, children's shyness contributed to their ratings of social competence. Specifically, teachers tended to rate shyer children higher than bolder children in two areas of social competence (cooperation and self-control), and bolder children higher than shyer children in one area of social competence (assertion). Second, shyness and attentional focusing (one facet of effortful control) worked together to contribute to children's kindergarten scores in one area of social competence (assertion). For shyer children, more attentional focusing contributed to higher assertion scores in kindergarten, whereas for bolder children, attentional focusing did not appear to contribute to assertion scores in kindergarten. Third, after we controlled for temperament characteristics, children's growth in assertion scores from kindergarten through second grade declined almost 10 points (out of 20 possible points). Fourth, both facets of effortful control (i.e., inhibitory control and attentional focusing) contributed to children's ratings of social competence, such that teachers rated children with greater inhibitory control and attentional focusing as more socially competent in cooperation and self-control. None of the described relationships were found to be gender related. Each of these findings is discussed below. 
Children's shyness contributed significantly to their social competence, but the direction of this relationship depended on the aspect of social competence under consideration. Specifically, shyer children were likely to be rated as more socially competent by teachers in the areas of cooperation and self-control, both of which relate to a child's ability to meet the academic and behavioral demands of the classroom. Children displaying high levels of cooperation respond readily to teacher directions and follow classroom rules, and children displaying high levels of self-control show restraint during classroom activities, displaying a quiet style that allows classroom discourse to function uninterrupted. The fact that shyer children were likely to be rated as highly cooperative and self-controlled is consistent with what we know about the characteristics of such children. Because they are withdraw-oriented, shyer children are unlikely to draw attention to themselves by disrupting class (e.g., calling out, talking with peers during quiet activities, or disobeying teacher commands). Instead, these children are typically quiet and obedient, have fewer social contacts in the classroom, and, therefore, have fewer avenues through which to disrupt class.

That shyer children were likely to have higher cooperation and self-control teacher ratings suggests that a behaviorally inhibited disposition works as a protective factor for children's adjustment to school. However, evidence from other studies suggests that this may be reflective of the fact that shyer children are simply not noticed as much by teachers as their bolder counterparts. For example, in recent examinations of the role of shyness and teacher-child relationship quality, Rudasill (2007) and Rydell et al. (2005) found that shyer children in preschool and first grade were more likely to have relationships with teachers that were low in conflict and closeness. In an examination of the characteristics of children who interact frequently with teachers, Coplan and Prakash (2003) found that, during free play, aggressive preschool children were most likely to solicit teachers' attention. Teachers, particularly novice teachers, worry about handling disruptive students. Such students pose the greatest challenge to the delivery of instruction, and teachers place emphasis on finding effective strategies for dealing with these students. Collectively, these studies (Coplan \& Prakash, 2003; Rudasill, 2007; Rydell et al., 2005) suggest that behaviorally inhibited children may fit so well into the role of student that they remain relatively unnoticed by teachers.

Shy children were rated by teachers as less assertive than their bolder peers. In addition, the characteristics of attentional focusing and shyness interacted to predict assertion, such that greater attentional focusing predicted more assertion for shyer children. These results are congruent with previous research showing that shyer children in preschool (Coplan \& Prakash, 2003) and fourth grade (Finn, Pannozzo, \& Voelkl, 1995) are less likely to engage classroom peers in interactions. In addition, the findings reported here suggest that attentional focusing serves as a protective factor for shyer children, providing the resources to over- 
come a withdrawal tendency and to engage with peers. Consider an example: A shy child is reluctant to join a new game on the playground. She watches attentively as the children play for a few minutes, focusing on the expectations and rules of the game. Then she asks a familiar child if she may join in. This shy child is using attentional focusing as a coping mechanism for overcoming her natural wariness about joining the game. She is overcoming her fear of the unfamiliar by becoming familiar through careful attention to the game. Although a child with an approach orientation may not hesitate to join an unfamiliar activity with peers, a child high in withdrawal may be reluctant to join, unless he or she has had an opportunity to become familiar with the activity.

After controlling for the contributions of temperament, children's assertion scores decreased substantially from kindergarten through second grade. Indeed, children's scores decreased almost 10 points, out of a possible 20 points, across the two years. Although initially counterintuitive, this finding may be explained by considering the demands that school places on children. The assertion subscale of the Social Skills Rating System measures a child's tendency to initiate interactions with peers; as children progress through early elementary school, there are fewer opportunities for child-initiated peer interactions (i.e., through play) and more demands on children to focus on teacher-directed instruction.

Inhibitory control and attentional focusing (i.e., effortful control) contributed to teachers' ratings of children's social competence as well. Children with high levels of inhibitory control and attentional focusing were rated higher on cooperation and self-control. These results are not surprising, given that effortful control is defined as the ability to inhibit an inappropriate response and activate an appropriate one (Kochanska et al., 2000). Students who are highly cooperative and show high levels of self-control are doing just that. Teachers see these children as readily responsive to teacher direction, good at following directions, and behaving in an orderly fashion during class activities. This suggests that children's effortful control is a protective factor for social competence, a finding that is supported by previous research (Eisenberg et al., 1995; Kochanska et al., 2000). In an examination of contributors to school readiness, Blair (2002) posited that the ability to regulate behavior (i.e., effortful control) contributes as much to children's readiness in school as intelligence. He pointed out that self-regulation is critical to children's abilities to adjust both academically and socially to the demands of school. Indeed, the demands on children's regulation are great in early elementary school; children must attend to classroom activities, listen to instructions, work with other children, stand in line, raise their hands, concentrate on assignments, and sit still for longer periods and more frequently than required prior to formal schooling.

Our results did not point to gender differences in terms of relationships between children's early temperament ratings and their social competence between kindergarten and second grade. This is incongruent with recent research suggest- 
ing that shyness in particular may be more deleterious to boys than girls (Coplan, Prakash, O’Neil, \& Armer, 2004; Rubin, Burgess, \& Coplan, 2002).

It is important to note that data for this study were collected at four different time points ( $4 \frac{1}{2} 2$ years, kindergarten, first grade, and second grade) by four different informants (mothers; and kindergarten, first-, and second-grade teachers), thus reducing the likelihood that associations between temperament and social competence were artifacts of associations between parents' and teachers' perceptions of children's characteristics. Much of the recent research on informant-based observations supports an apparent lack of agreement (or shared impression) between different informants rating the same child (McConaughy \& Ritter, 1995; Suen \& Ary, 1989). Although agreement between pairs of informants in similar settings (e.g., mother vs. father, or teacher-teacher pairs) is often reported as moderate in magnitude, relations of ratings between different informants from different settings (e.g., parents vs. teachers) are quite low (Achenbach, McConaughy, \& Howell, 1987; Canivez, Watkins, \& Schaefer; 2002; Ruffalo \& Elliott, 1997). For example, a large meta-analysis (Achenbach et al., 1987) of 269 data samples revealed an average correlation of .60 between pairs of parents and an average correlation of .28 between parents and teachers. The authors attributed the discrepancies to the fact that parents and teachers are not exposed to the same range of child behaviors in the setting in which they interact with the child.

\section{Limitations}

Two limitations should be noted. First, the assessments of social competence reported here may be elements of personality (i.e., agreeableness, extroversion, and conscientiousness) for which temperament is a precursor, rather than measures of learned social skills. That said, there is value in understanding how individual differences in temperament, which is generally conceptualized as biologically based (Kagan, 1998; Rothbart \& Bates, 1998, 2006; Thomas \& Chess, 1977), may relate to learned behaviors, such as skills associated with social competence. Indeed, many researchers have examined how early temperament may predict later behavior to better understand the contributions of temperament to a variety of outcomes (e.g., Sanson et al., 2004, provide a review of this literature for social outcomes). Second, although completed by different raters (mothers assessed temperament; and kindergarten, first-, and second-grade teachers assessed social competence), assessments of temperament and social competence would be strengthened with multiple raters and observational measures.

\section{Implications and Future Directions}

The findings from this study highlight the importance of considering child temperament characteristics when understanding children's social competence and, ultimately, successful adjustment to school. As such, these findings are informative for educational practice and research. The transition to school is both 
difficult and important for young children. The early elementary classroom places much greater social demands on children than those faced in preschool, in day care, or at home (Ladd et al., 2006). In addition, children's successful adjustment to school has implications for their social and academic outcomes for years beyond (Baker, 2006; Hamre \& Pianta, 2001; Ladd \& Price, 1987; Silver, Measelle, Armstrong, \& Essex, 2005). Recognizing the characteristics that children have prior to kindergarten that may facilitate or hinder adjustment through social competence during this critical transition can aid in preparing children for smoother adjustments. Such information may help parents, preschool teachers, and early elementary teachers prepare children who may be at particular risk for lower social competence.

The results reported here point to directions for future research. One direction is to investigate the extent to which quality of the classroom environment may moderate the relation between children's temperamental characteristics and their social competence in the classroom. It may be that highly supportive classrooms (i.e., where teachers are responsive and sensitive to students' needs and engage in primarily positive interactions with children) matter more for children who are at risk for difficulties with social competence. Currently there is a paucity of research examining interactions between children's temperament and the school environment (Sanson et al., 2004). Other important directions include examinations of the extent to which children's social competence mediates the relations between children's temperament and their academic (i.e., achievement measures) and social (i.e., peer relationships) outcomes in school. Most important, this study draws attention to children's temperament characteristics and how they may work together to contribute to an important competency for successful school transition, social competence.

Acknowledgments - This study was conducted by the National Institute of Child Health and Human Development (NICHD) Early Child Care Research Network supported by NICHD through a cooperative agreement that calls for scientific collaboration between the grantees and the NICHD staff. We would like to thank Timothy W. Curby for his assistance.

\section{References}

Achenbach, T. M., McConaughy, S. H., \& Howell, C. T. (1987). Child/adolescent behavioral and emotional problems: Implications of cross-informant correlations for situational specificity. Psychological Bulletin, 101, 213-232.

Asendorpf, J. B., \& Meier, G. H. (1993). Personality effects on children's speech in everyday life: Sociability-mediated exposure and shyness-mediated reactivity to social situations. Journal of Personality and Social Psychology, 64, 1072-1083.

Baker, J. A. (2006). Contributions of teacher-child relationships to positive school adjustment during elementary school. Journal of School Psychology, 44, 211-229.

Bentler, P. M., \& Bonett, D. G. (1980). Significance tests and goodness-of-fit in the analysis of covariance structures. Psychological Bulletin, 88, 588-606. 
Blair, C. (2002). School readiness: Integrating cognition and emotion in a neurobiological conceptualization of children's functioning at school entry. American Psychologist, 57, 111-127.

Browne, M. W., \& Cudeck, R. (1993). Alternative ways of assessing model fit. In K. A. Bollen \& J. S. Long (Eds.), Testing structural equation models (pp. 136-162). Newbury Park, CA: Sage.

Canivez, G. L., Watkins, M. W., \& Schaefer, B. A. (2002). Interrater agreement for discriminant classifications for the Adjustment Scales for Children and Adolescents. Psychology in the Schools, 39, 375-384.

Coplan, R. J., \& Armer, M. (2005). Talking yourself out of being shy: Shyness, expressive vocabulary, and socioemotional adjustment in preschool. Merrill-Palmer Quarterly, 51, 20-41.

Coplan, R. J., \& Prakash, K. (2003). Spending time with teacher: Characteristics of preschoolers who frequently elicit versus initiate interactions with teachers. Early Childhood Research Quarterly, 18, 143-158.

Coplan, R. J., Prakash, K., O'Neil, K., \& Armer, M. (2004). Do you "want" to play? Distinguishing between conflicted-shyness and social disinterest in early childhood. Developmental Psychology, 40, 244-258.

Coplan, R. J., Rubin, K. H., Fox, N. A., Calkins, S. D., \& Stewart, S. L. (1994). Being along, playing alone, and acting alone: Distinguishing among reticence and passive and active solitude in young children. Child Development, 65, 129-137.

Denham, S. A. (2006). Social-emotional competence as support for school readiness: What is it and how do we assess it? Early Education and Development, 17, 57-89.

Dodge, K. A., Coie, J. D., \& Lynam, D. (2006). Aggression and antisocial behavior in youth. In N. Eisenberg (Ed.), Social, emotional, and personality development (6th ed., Vol. 3, pp. 719-788). New York: Wiley.

Dodge, K. A., Pettit, G. S., McClaskey, C. L., \& Brown, M. M. (1986). Social competence in children. Monographs of the Society for Research in Child Development, 51 (2, Serial No. 213).

Eisenberg, N., Fabes, R. A., Murphy, B., Maszk, P., Smith, M. W., \& Karbon, M. (1995). The role of emotionality and regulation in children's social functioning: A longitudinal study. Child Development, 66, 1418-1438.

Eisenberg, N., Shepard, S. A., Fabes, R. A., Murphy, B. C., \& Guthrie, R. K. (1998). Shyness and children's emotionality, regulation, and coping: Contemporaneous, longitudinal, and across-context relations. Child Development, 69, 767-790.

Elliott, S. N., Malecki, C. K., \& Demaray, M. K. (2001). New directions in social skills assessment and intervention for elementary and middle school students. Exceptionality, 9, 19-32.

Fan, X., Thompson, B., \&Wang, L. (1999). The effects of sample size, estimation methods, and model specification on SEM fit indices. Structural Equation Modeling, 6, 56-83.

Finn, J. D., Pannozzo, G. M., \& Voelkl, K. E. (1995). Disruptive and inattentive-withdrawn behavior and achievement among fourth graders. Elementary School Journal, 95, 421-434.

Goldsmith, H. H., Aksan, N., Essex, M., Smider, N. A., \& Vandell, D. L. (2001). Temperament and socioemotional adjustment to kindergarten: A multi-informant perspective. In T. D. Wachs \& G. A. Kohnstamm (Eds.), Temperament in context (pp. 103-138). Mahwah, NJ: Erlbaum.

Gresham, F. M., \& Elliott, S. M. (1990). Social Skills Rating System Manual. Circle Pines, MN: American Guidance Service.

Hamre, B. K., \& Pianta, R. C. (2001). Early teacher-child relationships and the trajectory of children's school outcomes through eighth grade. Child Development, 72, 625-638.

Henderson, H. A., \& Fox, N. A. (1998). Inhibited and uninhibited children: Challenges in school settings. School Psychology Review, 27, 492-505. 
Hu, L., \& Bentler, P.M. (1995). Evaluating model fit. In R. H. Hoyle (Ed.), Structural equation modeling: Concepts, issues, and applications (pp. 76-99). Thousand Oaks, CA: Sage.

Hu, L., \& Bentler, P.M. (1999). Cutoff criteria for fit indexes in covariance structure analysis: Conventional criteria versus new alternatives. Structural Equation Modeling, 6, 1-55.

Kagan, J. (1994). Galen's prophecy: Temperament in human nature. New York: HarperCollins.

Kagan, J. (1998). Biology and the child. In N. Eisenberg (Ed.), Social, emotional, and personality development (5th ed., Vol. 3, pp. 177-236). New York: Wiley.

Kagan, J., \& Fox, N. (2006). Biology, culture, and temperamental issues. In N. Eisenberg (Ed.), Social, emotional, and personality development (6th ed., Vol. 3, pp. 167-225). New York: Wiley.

Kaplan, D. (1990). Evaluating and modifying covariance structure models: A review and recommendation. Multivariate Behavioral Research, 25, 137-155.

Kline, R. B. (2005). Principles and practice of structural equation modeling (2nd ed.). New York: Guilford Press.

Kochanska, G. (1997). Multiple pathways to conscience for children with different temperaments: From toddlerhood to age 5. Developmental Psychology, 33, 228-240.

Kochanska, G., Murray, K. T., \& Harlan, E. T. (2000). Effortful control in early childhood: Continuity and change, antecedents, and implications for social development. Developmental Psychology, 36, 220-232.

Ladd, G. W., Birch, S. H., \& Buhs, E. S. (1999). Children's social and scholastic lives in kindergarten: Related spheres of influence? Child Development, 70, 1373-1400.

Ladd, G. W., \& Burgess, K. B. (1999). Charting the relationship trajectories of aggressive, withdrawn, and aggressive/withdrawn children during early grade school. Child Development, 70, 910-929.

Ladd, G. W., Herald, S. L., \& Kochel, K. P. (2006). School readiness: Are there social prerequisites? Early Education and Development, 17, 115-150.

Ladd, G. W., \& Price, J. M. (1987). Predicting children's social and school adjustment following the transition from preschool to kindergarten. Child Development, 58, 1168-1189.

Mashburn, A. J., \& Pianta, R. C. (2006). Social relationships and school readiness. Early Education and Development, 17, 151-176.

McConaughy, S. H., \& Ritter, D. R. (1995). Best practices in multidimensional assessment of emotional or behavioral disorders. In A. Thomas \& J. Grimes (Eds.), Best practices in school psychology (Vol. 3, pp. 865-873). Washington, DC: National Association of School Psychologists.

National Institute of Child Health and Human Development, Early Child Care Research Network (1993). The NICHD study of early child care: A comprehensive longitudinal study of young children's lives. ERIC Document Reproduction Service, No. ED 3530870.

Pianta, R. C., Steinberg, M. S., \& Rollins, K. B. (1995). The first two years of school: Teacherchild relationships and deflections in children's classroom adjustment. Development and Psychopathology, 7, 295-312.

Rimm-Kaufman, S. E., \& Pianta, R. C. (2000). An ecological perspective on the transition to kindergarten: A theoretical framework to guide empirical research. Journal of Applied Developmental Psychology, 21, 491-511.

Rimm-Kaufman, S. E., Pianta, R. C., \& Cox, M. J. (2000). Teachers' judgments of problems in the transition to kindergarten. Early Childhood Research Quarterly, 15, 147-166.

Rothbart, M. K., Ahadi, A., \& Evans, D. E. (2000). Temperament and personality: Origins and outcomes. Journal of Personality and Social Psychology, 78, 122-135.

Rothbart, M. K., Ahadi, S. A., \& Hershey, K. L. (1994). Temperament and social behavior in childhood. Merrill-Palmer Quarterly, 40, 21-39.

Rothbart, M. K., \& Bates, J. E. (1998). Temperament. In N. Eisenberg (Ed.), Social, emotional, and personality development (5th ed., Vol. 3, pp. 105-176). New York: Wiley.

Rothbart, M. K., \& Bates, J. E. (2006). Temperament. In N. Eisenberg (Ed.), Social, emotional, and personality development (6th ed., Vol. 3, pp. 99-166). New York: Wiley. 
Rubin, K. H. (1982). Nonsocial play in preschoolers: Necessary evil? Child Development, 53, 651-657.

Rubin, K. H., Bukowski, W. M., \& Parker, J. G. (1998). Peer interactions, relationships, and groups. In N. Eisenberg (Ed.), Social, emotional, and personality development (5th ed., Vol. 3, pp. 619-700). New York: Wiley.

Rubin, K. H., Bukowski, W. M., \& Parker, J. G. (2006). Peer interactions, relationships, and groups. In N. Eisenberg (Ed.), Social, emotional, and personality development (6th ed., Vol. 3, pp. 571-645). New York: Wiley.

Rubin, K. H., Burgess, K. B., \& Coplan, R. J. (2002). Social withdrawal and shyness. In P. K. Smith \& C. H. Hart (Eds.), Blackwell's handbook of childhood and social development (pp. 329-352). London: Blackwell.

Rubin, K. H., Burgess, K. B., Dwyer, K. M., \& Hastings, P. D. (2003). Predicting preschoolers' externalizing behaviors from toddler temperament, conflict, and maternal negativity. Developmental Psychology, 39, 164-176.

Rubin, K. H., \& Coplan, R. J. (2004). Paying attention to and not neglecting social withdrawal and social isolation. Merrill-Palmer Quarterly, 50, 506-534.

Rubin, K. H., Coplan, R. J., Fox, N. A., \& Calkins, S. D. (1995). Emotionality, emotion regulation, and preschoolers' social adaptation. Development and Psychopathology, 7, 49-62.

Rudasill, K. M. (2007, March). Teacher-child relationship quality: The roles of behavioral inhibition, effortful control, and gender. Paper presented at the Society for Research in Child Development biennial conference. Boston, Massachusetts.

Ruffalo, S. L., \& Elliott, S. N. (1997). Teachers' and parents' rating of children's social skills: A closer look at cross-informant agreements through an item analysis protocol. School Psychology Review, 26, 489-501.

Rydell, A., Bohlin, G., \& Thorell, L. B. (2005). Representations of attachment to parents and shyness as predictors of children's relationships with teachers and peer competence in preschool. Attachment and Human Development, 7, 187-204.

Sanson, A., Hemphill, S. A., \& Smart, D. (2004). Connections between temperament and social development: A review. Social Development, 13, 142-170.

Schoen, M. J., \& Nagle, R. J. (1994). Prediction of school readiness from kindergarten temperament scores. Journal of School Psychology, 32, 135-147.

Silver, R. B., Measelle, J. R., Armstrong, J. M., \& Essex, M. J. (2005). Trajectories of classroom externalizing behavior: Contributions of child characteristics, family characteristics, and the teacher-child relationship during the school transition. Journal of School Psychology, 43, 39-60.

Skarpness, L. R., \& Carson, D. K. (1986). Temperament, communicative competence and the psychological adjustment of kindergarten children. Psychological Reports, 59, 1299-1306.

Suen, H. K., \& Ary, D. (1989). Analyzing quantitative behavioral observation data. Hillsdale, NJ: Erlbaum.

Tanaka, J. S. (1993). Multifaceted conceptions of fit in structural equation models. In K. S. Bollen \& J. S. Long (Eds.), Testing structural equation models (pp. 10-39). Newbury Park, CA: Sage.

Thomas, A., \& Chess, S. (1977). Temperament and development. Oxford, England: Brunner/ Mazel.

Thompson, R. A., \& Happold, C. A. (2002). The roots of school readiness in social and emotional development. Paper presented at the Kauffman Early Education Conference, Kansas City, Missouri.

Wichmann, C., Coplan, R. J., \& Daniels, T. (2004). The social cognitions of socially withdrawn children. Social Development, 13, 377-392.

Zill, N., Collins, M., West, J., \& Hausken, E. G. (1995). Approaching kindergarten: A look at preschoolers in the United States. Young Children, 51(1), 35-38. 